\section{Giant pulmonary aneurysm}

A 47-year-old man was referred to our hospital with progressive irritant dry coughing and dyspnea for 3 weeks. In the previous 4 months, he had experienced that his overall condition and training capacity in sports had decreased considerably.

A physical examination revealed chest area systolic jet noise. Laboratory tests showed a normal autoantibody spectrum and $\mathrm{PO}_{2}$ of $94.7 \mathrm{~mm} \mathrm{Hg}$ (normal value $107-116 \mathrm{~mm} \mathrm{Hg}$ ). Ultrasonography showed severe pulmonary valve stenosis without pulmonary hypertension.

Computed tomography three-dimensional reconstruction of the heart and large thoracic vessels revealed giant pulmonary aneurysms with a diameter of about $153 \mathrm{~mm}$ (Fig. 1). High-risk pulmonary artery (PA) aneurysms may be identified by evaluating: the causative mechanism(s) for PA dilatation, absolute PA diameter, and growth rate $(>75 \mathrm{~mm}$ and growth rate $>2 \mathrm{~mm} /$ year) (1).

After discussion with the medical team, we agreed that artificial blood vessel replacement might be the best choice. During the operation, we found no thrombus in the pulmonary aneurysm. The pulmonary arterial aneurysm was large, thin, and inelastic. We used artificial blood vessels to replace the pulmonary aneurysms and reconstruct the main PA and the initial part of the left PA (Fig. 2). After the operation, the patient recovered well and was discharged from the hospital.

PA aneurysm is a rare and multiform pathology related to multiple etiologies and therefore different pathophysiological mechanisms (2). We report this case of a giant pulmonary aneurysm

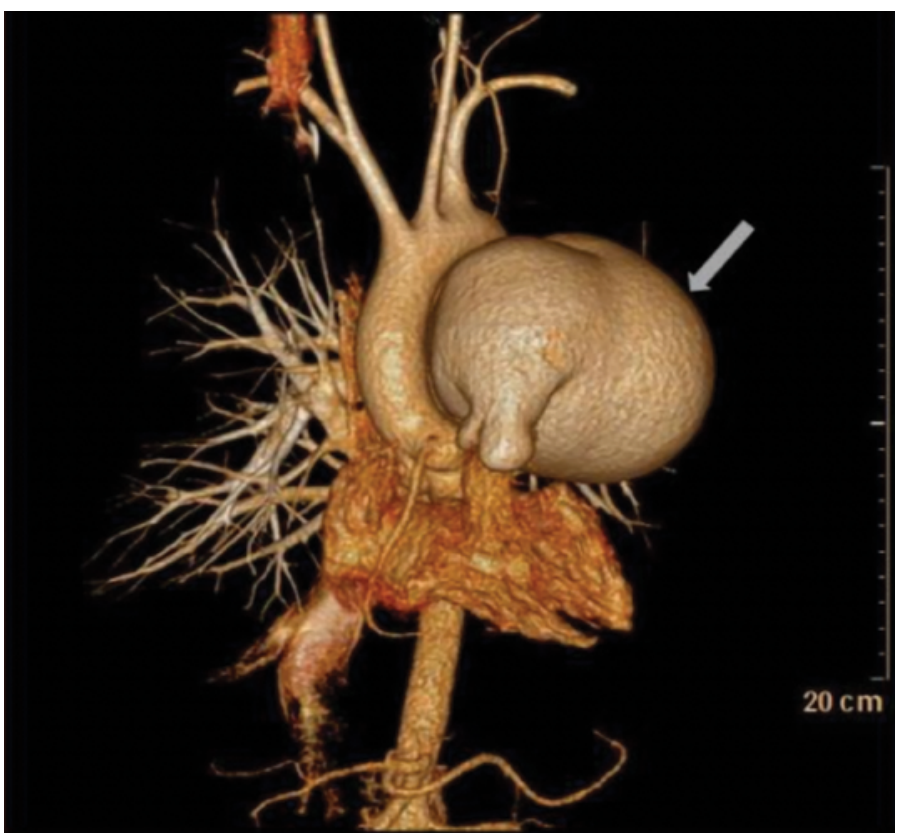

Figure 1. Preoperative CT three-dimensional reconstruction of the heart and large thoracic vessels. The giant pulmonary aneurysm (white arrow) was about $15 \mathrm{~cm}$ in diameter. The pulmonary aneurysm compresses the trachea and causes an irritant dry cough and dyspnea without pulmonary hypertension but associated to a dysplastic pulmonary valve. Severe pulmonary valve stenosis and congenital maldevelopment of the pulmonary arteries leads to the formation of giant pulmonary aneurysms.

Informed consent: Informed consent was obtained from the patient.

\section{References}

1. Duijnhouwer AL, Navarese EP, Van Dijk AP, Loeys B, Roos-Hesselink JW, De Boer MJ. Aneurysm of the Pulmonary Artery, a Systematic Review and Critical Analysis of Current Literature. Congenit Heart Dis 2016; 11: 102-9. [CrossRef]

2. Radermecker A, Stiennon L, Leroux A, Sooknunden M, Duysinx B, Guiot $\mathrm{J}$, et al. Giant pulmonary artery aneurysms. Case report and proposal of management algorithm. Rev Med Liege 2019; 74: 90-4.

\section{(D) Jianglong Hou, (1) Yibing Fang \\ Department of Cardiovascular Surgery, West China Hospital of Sichuan University; Chengdu-China}

Address for Correspondence: Jianglong Hou, MD,

Department of Cardiovascular Surgery,

West China Hospital of Sichuan University;

No.37 Guo Xue Alley 61004,

Chengdu-China

Phone: +86 02885421833

E-mail: houjianglong@wchscu.cn - jianglonghou@scu.edu.cn

(C) Copyright 2020 by Turkish Society of Cardiology - Available online at www.anatoljcardiol.com

DOI:10.14744/AnatolJCardiol.2020.57598

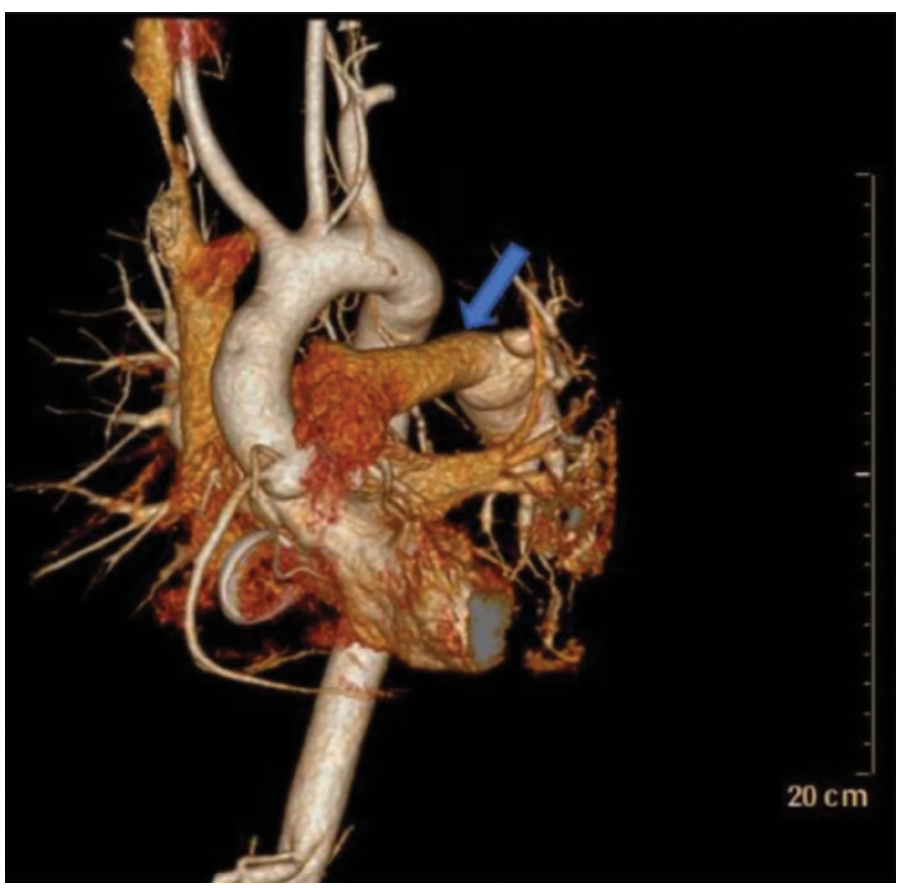

Figure 2. Postoperative CT three-dimensional reconstruction of the heart and large thoracic vessels. We used artificial blood vessels (Gore-Tex $20 \mathrm{~mm}$, blue arrow pointed) to replace the pulmonary aneurysms and reconstruct the main pulmonary artery and the initial part of the left pulmonary artery 